\title{
Modelagem espaço-temporal da erosão e potencial contaminação de Arsênio e Chumbo na bacia hidrográfica do rio Ribeira de Iguape (SP)
}

\author{
Fabiane Hilario dos Santos Costa ${ }^{1}$, Carlos Roberto de Souza Filho ${ }^{1}$ \& Alfonso Risso $^{2}$
}

\begin{abstract}
Resumo A simulação de um ambiente natural através de técnicas computacionais é um tema de pesquisa bastante promissor para o planejamento e tomada de decisões ambientais. A erosão hídrica no solo inicia-se com o impacto da gota de chuva sobre sua superfície. Numa situação onde a erosividade da chuva é elevada, pode ocorrer cisalhamento hidraúlico do solo e transporte dos sedimentos. Na busca por uma melhor compreensão sobre as dimensões espaço-temporais desses fenômenos naturais, este trabalho visou a caracterização da erosão potencial de uma área inserida na Bacia Hidrográfica do Rio Ribeira de Iguape, utilizando a Equação Universal de Perdas de Solos (EUPS), através de Geotecnologias e rotinas computacionais. O período considerado na análise foi entre 1990 e 1999, dentro do qual foram comparadas áreas de ocorrência espacial simultânea de alto potencial erosivo e alto teor de $\mathrm{Pb}$ e As, fruto de uma anomalia natural existente neste local. Esta aplicação multitemporal mostrou a tendência evolutiva dos processos erosivos na região, principalmente os compreendidos nas áreas relacionadas às anomalias de $\mathrm{As} \mathrm{e} \mathrm{Pb.} \mathrm{Áreas} \mathrm{com} \mathrm{perdas} \mathrm{de} \mathrm{solo} \mathrm{acima} \mathrm{de} 200 \mathrm{t} /$ ha.ano foram identificadas, as quais devem ser consideradas como em processo de degradação do solo e fonte de elementos tóxicos sob dispersão no meio ambiente.
\end{abstract}

Palavras-chave: erosão potencial, perda de solo, EUPS, arsênio, Rio Ribeira de Iguape.

\begin{abstract}
Spatio-Temporal modeling of erosion and potential contamination ofArsenic and Lead in the Ribeira de Iguape river watershed (state of São Paulo, Brazil). The simulation of a natural environment through computational techniques is a promising research theme that can append advantages for planning and decisions on environmental issues. Hydric erosion is triggered by the impact of rain drops on the soil surface. If rain-induced erosion is high, soil undergoes through hydraulic shearing and the yielded sediments are consequently transported. In the search for a better understanding of space-time dimensions of such natural phenomena, this work aimed to characterize the potential erosion of a selected area located in the Ribeira de Iguape River Hydrographic Basin. This was achieved using the Universal Soil Loss Equation (USLE) through Geotechnologies and computational routines. The period considered in the analysis spans between 1990 and 1999, within which areas with spatial coincidence of high erosive potential and high $\mathrm{Pb}$ and $\mathrm{As}$ content in soil (associated to a pre-existing, natural As anomaly) were compared. This multitemporal application showed the evolutionary trend of the erosive processes in the region, effectively those associated to the $\mathrm{As}$ and $\mathrm{Pb}$ anomalies. Areas with soil losses above $200 \mathrm{t} / \mathrm{ha}$.year were identified, which ought to be considered in the process of land degradation and source of toxic elements under dispersion in the environment.
\end{abstract}

Keywords: potential erosion, soil loss, USLE, arsenic, Ribeira de Iguape River.

INTRODUÇÃO O aumento da atividade humana ao longo dos séculos tem provocado importantes alterações e conseqüentes impactos sobre o meio ambiente. A crescente necessidade de apresentar soluções e estratégias que interrompam e revertam os efeitos da degradação ambiental e do esgotamento dos recursos naturais vem se fortalecendo cada vez mais, provocando uma série de questionamentos. As discussões atuais sobre problemas relacionados ao meio ambiente e seus reflexos na qualidade de vida de diversas comunidades e sobre o futuro do planeta têm levado em conta o papel dos recursos geológicos, pedológicos, hídricos, atmosféricos e biológicos, nos quais ocorrem as maiores agressões e impactos ao meio ambiente (White et al. 1992).
As partículas (sólidos) transportadas pelos cursos de água têm origem, principalmente, na erosão superficial do solo. As gotas de chuvas, caindo na superfície do solo, o desagrega, removendo-o. Esse processo é tão mais intenso quanto menor a cobertura vegetal, maior a intensidade da chuva, maior o grau de declive e maior for à susceptibilidade do solo à erosão (Ranieri et al. 1998).

A intensidade da erosão está intimamente associada à erosividade das chuvas, a erodibilidade do solo, ao comprimento da rampa e grau do declive das vertentes, às características do solo e o seu uso e manejo. Os sedimentos removidos de uma bacia durante chuva intensa podem ficar depositados em um alvéolo fluvial e

1 - Universidade Estadual de Campinas, Instituto de Geociências, DGRN, Campinas (SP), Brasil. E-mails: fabianehsc@hotmail.com, beto@ige.unicamp.br

2 - Universidade Federal do Rio Grande do Sul, Instituto de Pesquisas Hidráulicas, Porto Alegre (RS), Brasil. E-mail: risso@iph.ufrgs.br 
ali permanecerem até outra precipitação, quando serão transportados para jusante (Lopes 1980).

A erosão hídrica (laminar) é um dos tipos de erosão mais importantes, porém dificilmente perceptível. O início desse fenômeno ocorre quando as gotas de chuva atingem o solo. Nesse momento, o solo tem seus grânulos e torrões rompidos e transformados em pequenas partículas, o que causa uma diminuição na capacidade de infiltração de água no terreno (Resende \& Almeida 1985). Embora a erosão seja um processo natural, esta pode ser acelerada ou retardada pela ação antrópica. Bertoni \& Lombardi Neto (1993) constataram que uma única chuva pode provocar o desprendimento de mais de 200 toneladas de partículas de solo por hectare.

Um problema que a ciência vem enfrentando é a quantificação de erosão tolerável ou permissível. Para tanto se tornam indispensáveis estudos que avaliem a susceptibilidade dos diferentes tipos de solo aos processos erosivos, as taxas com que esses processos ocorrem, suas conseqüências na paisagem, além do conhecimento dos prováveis fatores desencadeadores.

Este trabalho visa quantificar a erosão hídrica e sua possível relação com anomalias de arsênio e chumbo numa área piloto na região do Vale do Ribeira, utilizando a Equação Universal de Perdas de Solos (EUPS), de forma integrada e sistematizada ao ambiente de um Sistema de Informações Geográficas (SIG). Para tanto, serão gerados mapas temporais de potenciais de erosão e mapas de anomalias geoquímicas de arsênio e chumbo. A comparação entre esses mapas permitirá a discriminação de áreas em que há uma maior exposição de sedimentos enriquecidos nestes elementos tóxicos.

As atividades mineiras do Vale do Ribeira, que remontam ao século XVII, foram marcadas por intensa exploração de $\mathrm{Pb}$ durante praticamente todo o século XX. A área específica compreendida nessa investigação hospeda a ocorrência de anomalias naturais de As e outros elementos traço $(\mathrm{Cu}, \mathrm{Cr}, \mathrm{Ni}, \mathrm{Pb}$ e $\mathrm{Zn})$, potencialmente prejudiciais à saúde humana e animal. Esse aspecto, somado a outros econômicos e ambientais regionais, formam um cenário ideal para pesquisas de diagnósticos e avaliação de riscos na região. Além disso, a área foi selecionada para estudo em função da abundante malha amostral de dados geoquímicos gerados pelo Instituto de Pesquisas Tecnológicas (IPT) e pela Companhia de Pesquisa e Recursos Minerais (CPRM).

ÁREA DE ESTUDO A Bacia Hidrográfica do Rio Ribeira de Iguape (Fig. 1), o Complexo Estuarino Lagunar de Iguape-Cananéia-Paranaguá e as diversas bacias hidrográficas encaixadas entre esta e o Oceano Atlântico, genericamente denominada Vale do Ribeira, possuem uma área de 2.830.666 hectares (28.306 $\mathrm{km}^{2}$ ), abrangendo as regiões sul do estado de São Paulo (1.711.533 ha) e leste do estado do Paraná (1.119.133 ha), (ISA 1998).

Esse conjunto está compreendido, em sua totalidade, em clima sub-tropical úmido, sem estação seca. A diferença de altitude condiciona variações climáticas locais. Regiões que apresentam altitudes superiores a
1000 m estão situadas no domínio climático mesotérmico brando, superúmido, com sub-seca, caracterizado por apresentar temperatura média anual em torno de $18^{\circ} \mathrm{C}$ (cf. classificação proposta por Nimer 1977) para as regiões sul e sudeste do Brasil.

Na geologia da área, segundo Perrotta (1996), predominam filitos carbonosos com espessas intercalações de rochas metabásicas e metaultrabásicas, quase sempre afetadas por alteração hidrotermal dos tipos cloritização e/ou carbonatação. Sericita-quartzo filitos ocorrem como intercalações centimétricas freqüentes, ou localmente como lentes espessas. Rochas metaultrabásicas desta seqüência têm assinaturas químicas de vulcanismo basanítico de regime tectônico distensivo, distinto das metabásicas das unidades adjacentes, de composição basáltica, filiação toleítica e afinidade MORB/arco insular vulcânico.

$\mathrm{O}$ arcabouço estrutural desta região é definido por um sistema anastomosado de zonas de cisalhamento transcorrentes de caráter dúctil a dúctil-rúptil. Zonas de cisalhamento sub-horizontais, de expressão menos significativa na área, são atribuídas a eventos deformais anteriores e contemporâneos às transcorrências (Perrotta 1996).

\section{ARSÊNIO E CHUMBO NO MEIO AMBIEN-}

TE Os ambientes geográficos têm uma relação intima com as doenças endêmicas e são influenciados pelo clima, geologia, relevo, solo, alimentação e água potável. Diversas são as interações entre o meio ambiente e o homem, o que certamente reflete-se na saúde.

A rocha pode influenciar a estrutura e o componente químico do solo, como também das águas superficiais e subterrâneas. Elementos como As, $\mathrm{Pb}, \mathrm{Cd}, \mathrm{Cr}$, Sn, $\mathrm{F}, \mathrm{Be}, \mathrm{Se}, \mathrm{Hg}$ e Ti podem se acumular em solos e corpos d'água, potencializando doenças nos seres humanos, como fluorose, toxicose de selênio, arsenismo, toxicose de cádmio, etc (Wang \& Zhang 1985; Lin 1991).

A disponibilidade dos elementos depende essencialmente de sua presença na solução do solo, que é governada pela composição e reação do solo, pelas condições de oxi-redução e pela cinética das reações. Essas variáveis dependem não somente das características do solo, mas também de sua tendência à formação de precipitados insolúveis, co-precipitados com outros minerais e complexos com a matéria orgânica (Ferreira et al. 2001) .

A ação química dos metais pesados tem despertado grande interesse ambiental. Isto se deve, em parte, pelo fato de não possuírem caráter de biodegradabilidade, o que determina que permaneçam em ciclos biogeoquímicos globais nos quais as águas naturais são seus principais meios de condução, podendo-se acumular na biota aquática em níveis significativamente elevados (Silva 2002).

A toxicidade do arsênio, assim como ocorre para outros metalóides e para os metais pesados, é maior em temperaturas mais elevadas e também em águas brandas e de $\mathrm{pH}$ ácido. Os efeitos da ingestão acentuada de arsênio, que ocorre principalmente pelo consumo de águas ricas neste elemento, estão associados ao desenvolvimento de tumores, notadamente nos rins e no fígado, além da formação de ceratoses, que 


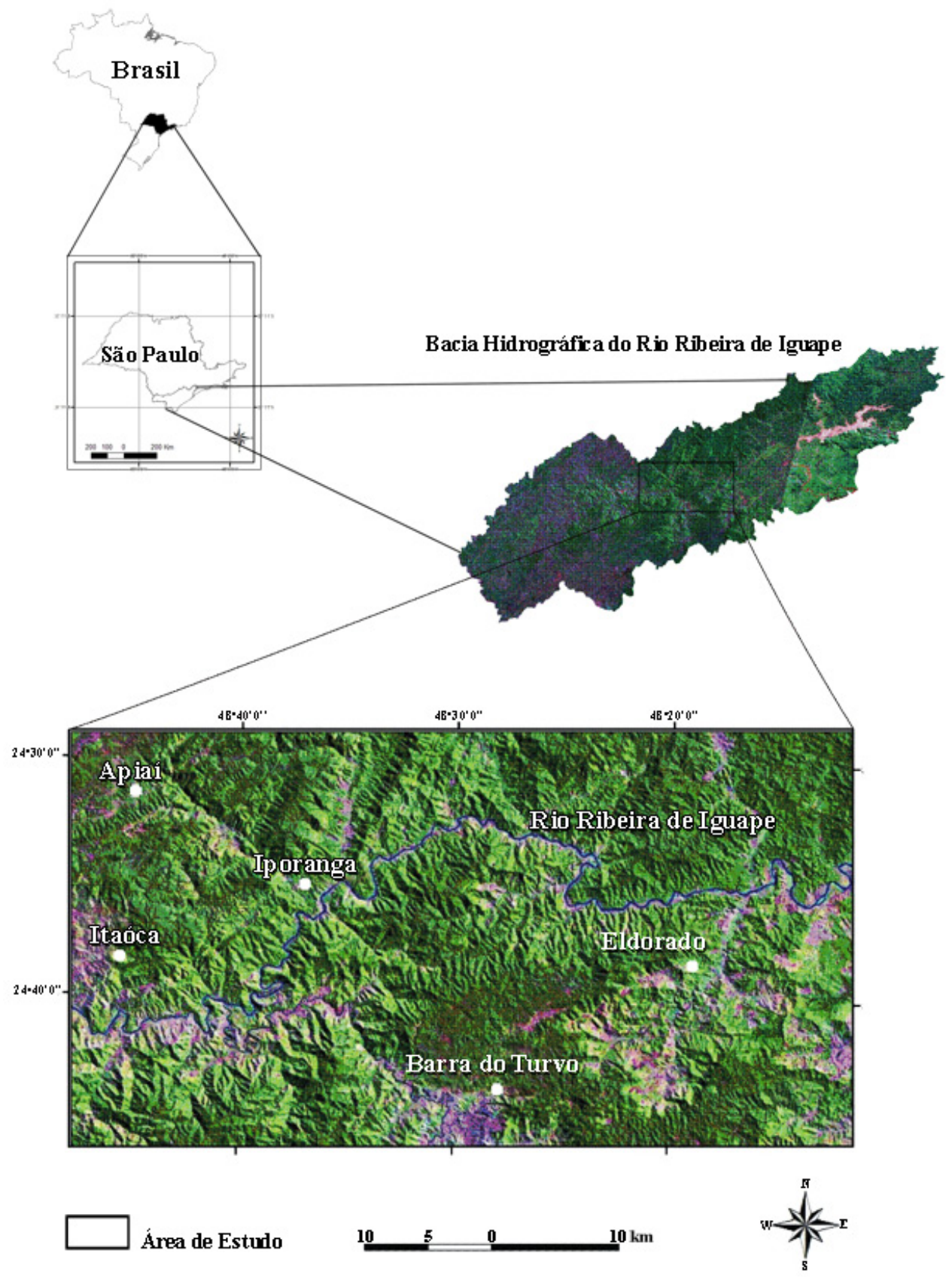

Figura 1 - Localização da Bacia Hidrográfica do Rio Ribeira de Iguape e da área de estudo.

consistem no crescimento anormal de substância córnea na epiderme, semelhantes a grandes calosidades. A intoxicação por arsênio (arsenicose) induz ainda a distúrbios gastro-intestinais e a danos cardíacos de magnitude variada (CCME 1999).

Para a população em geral, a exposição ao chumbo ocorre principalmente por via oral, com alguma contribuição por via respiratória. Na exposição ocupacional, a via principal é a inalatória. A plumbemia reflete a dose absorvida de chumbo e a quantidade biologicamente ativa no organismo. Entretanto, como a maior parte da carga corpórea do chumbo se encontra nos ossos, esse metal tem uma meia-vida biológica longa e, portanto, a interpretação dos dados de plumbemia depende do conhecimento da exposição ao metal. Quanto aos efeitos sistêmicos deste metal podem ser citados os cardiovasculares, gastrintestinais, hematológicos, renais, imunológicos e neurológicos (Zwennis et al. 1990).

A importância da caracterização do arsênio e chumbo, no presente trabalho, se dá porque os solos se apresentam não apenas como um dreno para contaminantes, mas também como tampões naturais que controlam o transporte de elementos químicos e outras substâncias para a atmosfera, hidrosfera e biota.

MATERIAIS Duas imagens digitais do sensor TM (Thematic Mapper) e ETM+ (Enhanced Thematic Mapper Plus), respectivamente, dos satélites LANDSAT 5 e 7 (órbita 220, ponto 077), obtidas em 09 de setembro de 1990 e 26 de setembro de 1999, foram utilizadas 
para geração do mapa de uso e ocupação temporal.

O mapa pedológico do Vale do Ribeira, no estado de São Paulo, foi produzido pelo Instituto Agronômico e digitalizado. O mapa equivalente no estado do Paraná foi produzido pela Mineropar e disponibilizado em formato digital. Ambos foram originalmente gerados na escala 1:250.000.

$\mathrm{O}$ modelo numérico do terreno (MNT) utilizado foi derivado de dados altimétricos obtidos no programa SRTM (Shuttle Radar Topography Mission) (Rodriguez et al. 2005), após correção de valores nulos e aumento da resolução espacial de $90 \mathrm{~m}$ para $30 \mathrm{~m}$ (Valeriano, 2005).

A base de dados geoquímicos utilizada foi gerada pelo Serviço Geológico do Brasil - CPRM (Addas \& Vinha 1975, Morgental et al. 1975, Morgental et al. 1978, Alegri et al. 1980, Silva 1982). Os elementos aqui empregados foram o arsênio e o chumbo. As amostras compreendem sedimentos de corrente ativa, os quais foram peneirados a 80 mesh e analisados por espectrometria de emissão óptica (EO) e espectrometria de absorção atômica (AA). Dados de arsênio e chumbo derivados do projeto de geoquímica regional do IPT (1985) também foram utilizados no estudo. Nesse projeto do IPT foram analisadas amostras de sedimentos de corrente, na fração inferior a 80 mesh. Para a detecção do arsênio e chumbo foram utilizados, respectivamente, os métodos de AA e EO.

Os dados pluviométricos foram disponibilizados pelo DAEE (2008).

\section{MÉTODOS}

Modelo EUPS (Equação Universal de Perda de Solo) O modelo EUPS visa quantificar o transporte e a deposição de solo por processo de erosão hídrica. É a relação empírica mais amplamente utilizada e tem passado por várias atualizações (Lopez 1993).

O processo de erosão ocorre basicamente pelo efeito da energia cinética das gotas de chuva sobre o solo, deslocando suas partículas, que podem ser arrastadas pelas enxurradas e depositadas num local de menor velocidade (Resende \& Almeida 1985).

A erosão hídrica é causada por (i) forças ativas, tais como chuva com características específicas, declividade, comprimento da vertente do terreno e capacidade de absorção de água pelo solo; e (ii) por forças passivas, como a resistência que o solo exerce sobre a ação erosiva da água e a densidade de cobertura vegetal (Bertoni \& Lombardi Neto 1993).

Os valores quantitativos de perda de solo potencial gerado pela equação, ou outros modelos de simulação, devem ser considerados como estimativas para fins comparativos, principalmente como uma análise qualitativa da distribuição espacial do potencial erosivo. O ideal é que esses valores sejam obtidos a partir de experimentos de campo.

Em meados do século XX, pesquisadores americanos conseguiram aprimorar as equações para cálculo de perdas de solos que são usadas atualmente. O método mais usado, a EUPS, foi proposta por Wischmeier \& Smith (1965 - apud Bertoni \& Lombardi Neto 1993). A equação 1 é assim expressa:

$$
\mathbf{A}=\mathbf{R} * \mathbf{K} * \mathbf{L S} * \mathbf{C P}
$$

onde:

$\mathrm{A}=$ Quantidade de terra removida, em toneladas por hectares.

$\mathrm{R}=($ erosividade $)=$ Índice de erosão causada pela chuva (Mj.mm/h.ha).

$\mathrm{K}=($ erodibilidade do solo $)=$ Intensidade de erosão por unidade de índice de erosão da chuva para um solo específico, que é mantido continuamente sem cobertura, mas submetido as atividades usuais de manejo de culturas.

$\mathrm{L}=($ comprimento do declive $)=$ Relação de perdas de solo entre o comprimento de declive qualquer e um comprimento de rampa de $25 \mathrm{~m}$ para o mesmo solo e grau de declive;

$\mathrm{S}=($ grau de declive $)=$ relação de perdas de solo entre um declive qualquer e um declive de $9 \%$ para o mesmo solo e comprimento de rampa.

$\mathrm{P}=($ práticas conservacionistas $)=$ Relação entre as perdas de solo de um terreno cultivado com determinada prática agrícola e as perdas quando a cultura é plantada morro abaixo. São utilizadas tabelas referentes às práticas conservacionistas.

$\mathrm{C}=($ uso e manejo $)=$ Relação entre as perdas de solo de um terreno cultivado em dadas condições e as perdas correspondentes de um terreno mantido continuamente descoberto.

Os fatores RKLS dependem das características naturais, enquanto que o $\mathrm{C}$ e o $\mathrm{P}$ estão relacionados às formas de ocupação e uso da terra. Portanto, as mudanças no estilo de atuação dos primeiros dependem de alterações ambientais, tais como mudanças climáticas ou erosões importantes, que possam alterar a topografia, por exemplo. Porém o CP pode ser alterado por ações de uso do solo e de conservação.

EROSIVIDADE (R) A Erosividade (R) pode ser definida como uma avaliação numérica da capacidade de uma tormenta ou de uma precipitação erodir os solos de uma área desprotegida. É representada através de isolinhas em mapas de isoerodentes.

Lombardi Neto \& Moldenhauer (1980) aplicaram o método desenvolvido por Wischmeier (1959) em Campinas-SP e propuseram a determinação do valor médio de índice de erosividade através da relação entre a média mensal e a média anual de precipitação, conforme a seguinte equação 2 :

$$
\mathrm{EI}^{30}=67,355\left(\mathrm{r}^{2} / \mathrm{P}\right)^{0,86}
$$

onde:

$\mathrm{EI}^{30}=$ média mensal do índice de erosividade, MJ.mm(ha.h)

$\mathrm{r}=$ média do total mensal de precipitação, em $\mathrm{mm}$

$\mathrm{P}=$ média total anual de precipitação, em $\mathrm{mm}$

O fator R (Tab.1) é obtido através da soma do resultado dos valores mensais do índice de erosividade em cada estação pluviométrica. O fator R para a área de estudo foi estimado a partir de dados pluviométri- 
Tabela 1 - Fator R: Erosividade da chuva da área de estudo (fonte: DAEE, 2008).

\begin{tabular}{c|c|c|c}
\hline \multirow{2}{*}{ Período } & \multicolumn{3}{|c}{ Erosividade (MJ.mm/ha.h.ano) } \\
\cline { 2 - 4 } & Mínima & Máxima & Média \\
\hline $1960-2000$ & 2784 & 11804 & 7294 \\
\hline
\end{tabular}

cos correspondentes a dois períodos de tempo ininterruptos, nos postos de Apiaí, Itapeúna, Itaóca, Gritador, Barra do Turvo e Cajati (DAEE 2008). A análise destes períodos visou identificar alterações temporais referentes à erosividade da chuva na área de estudo.

ERODIBILIDADE (K) A erodibilidade (K) do solo é a sua vulnerabilidade ou suscetibilidade à erosão, que é a recíproca da sua resistência à erosão. A erodibilidade de um solo pela água é determinada (i) pelas suas propriedades intrínsecas, que afetam a velocidade de infiltração da água, permeabilidade e a capacidade de absorção da água pelo solo; e (ii) por propriedades que conferem resistência à dispersão, ao salpicamento, à abrasão e as forças de transporte da chuva e enxurrada (Bertoni \& Lombardi Neto 1993).

Os valores para o fator K (Tab. 2) dos solos da área de estudo foram estimados a partir dos valores sugeridos no Plano de Conservação da Bacia do Alto Paraguai (PCBAP 1997).

A espacialização do fator $\mathrm{K}$ foi obtida a partir da reclassificação numérica dos mapas pedológicos disponíveis na escala 1:250.000 para bacia hidrográfica do rio Ribeira de Iguape.

FATOR TOPOGRÁFICO (LS) A intensidade da erosão hídrica é variável e depende de características da rampa que a água percorre, particularmente do seu comprimento (L) e grau de declive (S). Essas duas variáveis são pesquisadas separadamente, mas para apli- cação na EUPS, são analisadas conjuntamente, constituindo o fator topográfico (LS) (Fujihara 2002). O fator LS representa a relação esperada de perda de solo por unidade de área em um declive qualquer, comparada à perda de solo correspondente em uma parcela unitária padrão de 25 metros de comprimento com $9 \%$ de declividade (Bertoni \& Lombardi Neto 1993). A EUPS utiliza um índice adimensional referente ao fator declividade como uma das variáveis topográficas.

O cálculo do fator LS para a equação de perdas de solo é baseado na fórmula 3 (Bertoni \& Lombardi Neto 1993):

$$
\text { LS }=0,00984 * C^{0,63 *} D^{1,18}
$$

onde:

$\mathrm{LS}=$ fator topográfico

$\mathrm{C}=$ comprimento de rampa em metros

$\mathrm{D}=$ grau de declive em porcentagem

Esses valores podem ser obtidos com ábacos, manualmente sobre as bases cartográficas, ou por meio do geoprocessamento. Neste estudo utilizou-se um algoritmo denominado Usle2D (Van Oost \& Govers 2000).

O algoritmo Usle2D foi desenvolvido para estimar os fatores topográficos a partir de Modelos Numéricos de Terreno (MNT). O fator combinado LS associa o fator de comprimento de rampa e o fator declividade. Esta associação pode ser feita por meio da equação 4 desenvolvida por Wischmeier (1959):

$$
0,065) \quad L S=(\lambda / 22,13)^{\mathrm{m}} *\left(65,41 \operatorname{sen}^{2} \theta+4,56 \operatorname{sen} \theta+\right.
$$

onde:

$\lambda$ : comprimento de rampa em metros, calculada como projeção horizontal

$\theta$ : ângulo da rampa

$\mathrm{m}$ : expoente, função da declividade (s em \%)

Especificamente no algoritmo Usle2D, o valor

Tabela 2 - Fator K: Erodibilidade dos solos da área de estudo (fonte: PCBAP 1997).

\begin{tabular}{l|l|l|l}
\hline Legenda & Classe & Descrição & K (t.h/(MJ.mm)) \\
\hline $\mathrm{Bv}$ & Brunizém Avermelhado & & 0.038 \\
\hline $\mathrm{Ca}$ & Cambissolo álico & Pouco profundo, erodível & 0.06 \\
\hline $\mathrm{Cd}$ & Cambissolo distrófico & Pouco profundo, erodível & 0.06 \\
\hline $\mathrm{Ce}$ & Cambissolo eutrófico & Pouco profundo, erodível & 0.06 \\
\hline $\mathrm{Gd}$ & SolosGleizados distrófico & $\begin{array}{l}\text { Mal drenados, áreas baixas (recebe } \\
\text { sedimentos) }\end{array}$ & 0.00 \\
\hline $\mathrm{LAa}$ & Latossolo Amarelo álico & Boa aptidão agrícola & 0.02 \\
\hline $\mathrm{LVa}$ & $\begin{array}{l}\text { Latossolo Vermelho-Amarelo } \\
\text { distrófico }\end{array}$ & Média aptidão & 0.02 \\
\hline $\mathrm{PVa}$ & Podzólico Vermelho-Amarelo álico & Média aptidão, erodibilidade média & 0.043 \\
\hline $\mathrm{PVd}$ & $\begin{array}{l}\text { Podzólico Vermelho-Amarelo } \\
\text { distrófico }\end{array}$ & Média aptidão, erodibilidade média & 0.043 \\
\hline $\mathrm{Ra}$ & Litólico álico & $\begin{array}{l}\text { baixa aptidão, pouco profundos, } \\
\text { erodibilidade alta }\end{array}$ & 0.054 \\
\hline $\mathrm{TBd}$ & Terra Bruna Estruturada distrófica & Baixa aptidão, erodibilidade alta & 0.018 \\
\hline
\end{tabular}


linear de $\lambda$ é estimado como um valor de referência equivalente, correspondente ao comprimento de rampa médio da bacia contribuinte a montante de cada célula do MNT.

Por ser uma matriz de dados altimétricos, com forma e espaçamento constantes, o MNT proporcionado pelo SRTM é conceitualmente completo para interpolação através técnica de krigagem, visando a reamostragem para uma resolução superior, de $30 \mathrm{~m}$, compatível com a resolução de outros dados utilizados nesse trabalho. A função é um método de regressão usado para aproximar (interpolar) dados, e parte do princípio que pontos próximos no espaço tendem a ter valores mais parecidos do que pontos mais afastados (e.g., Valeriano 2002). Todo processo é baseado no cálculo da função variograma e na modelagem gráfica do semivariograma, de forma a preservar a característica original do terreno estudado. $\mathrm{O}$ variograma foi calculado a partir dos resíduos da análise da superfície de tendência de primeira ordem, de forma a garantir que dados geoestacionários fossem modelados.

Realizado este procedimento, os dados foram então utilizados para a obtenção de uma matriz numérica com a distribuição espacial do fator LS.

USO E MANEJO (C) E PRÁTICAS CONSERVACIONISTAS (P) O fator CP (Tab. 3) é outro índice combinado da EUPS. O fator de uso e manejo do solo $\mathrm{C}$ representa a relação esperada entre as perdas de solo em um terreno cultivado e em um terreno com solo exposto. O seu valor vai depender do tipo de cultura e manejo adotado, da quantidade de chuvas, da fase do ciclo vegetativo, entre outras variáveis, cujas combinações apresentam diferentes efeitos na perda de solo.

Trata-se da relação entre a intensidade esperada de perda de solo com determinada prática conservacionista ou quando a cultura está disposta no sentido do declive. Uma área sem proteção de cobertura vegetal é geralmente mais suscetível à erosão do que uma que esteja recoberta por vegetação, sendo que o seu efeito dependerá do tipo e fase do crescimento da vegetação associada à seqüência de culturas e ao manejo (Bertoni \& Lombardi Neto 1993).

Obtenção do Fator CP $\mathrm{O}$ fator $\mathrm{CP}$ foi gerado através do processamento das duas imagens Landsat. Dentre as 7 bandas espectrais cobertas por esses sensores, foram utilizadas apenas as bandas 3 (vermelho: $0.63-0.69$ $\mu \mathrm{m}), 4$ (infravermelho próximo: $0.76-0.90 \mu \mathrm{m}$ ) e 5 (infravermelho médio: 1.55 - 1. $75 \mu \mathrm{m}$ ), que apresentam resolução espacial análoga (30 metros) e maior interesse pelas suas características espectrais em função das necessidades de mapeamento deste trabalho.

As imagens foram classificadas através de um algoritmo de segmentação, que é uma técnica de agrupamentos de dados, na qual somente as regiões espacialmente adjacentes e de características espectrais semelhantes podem ser agrupadas. Para realizar o processo de segmentação foi necessário definir dois limiares: a) o limiar de similaridade, valor mínimo estabelecido pelo intérprete, abaixo do qual duas regiões são consi-
Tabela 3 - Fator CP: Cobertura e práticas conservacionistas adotadas para os solos da área de estudo (adaptado de Risso et. al. 2005).

\begin{tabular}{l|l|l}
\hline Legenda & Classificação & $\mathrm{CP}$ \\
\hline $\mathrm{Md}$ & Mata Densa & 0.0005 \\
\hline $\mathrm{Mr}$ & Mata Rala & 0.0005 \\
\hline $\mathrm{C}$ & Campo & 0.01 \\
\hline $\mathrm{Cs}$ & Campo Sujo & 0.01 \\
\hline $\mathrm{Se}$ & Solo Exposto & 0.2 \\
\hline
\end{tabular}

deradas espectralmente similares e agrupadas em uma única região; b) o limiar de área, valor de mínima dimensão, dado em número de pixels, para que uma região seja individualizada (Fonseca 2001).

A avaliação do processo de segmentação foi realizada por meio da comparação visual entre a imagem segmentada e a imagem realçada. Essa metodologia foi adotada pois é uma forma qualitativa, mas eficiente, para avaliar o resultado da segmentação (Cross et al. 1988). A partir dessa classificação foi obtido um mapa de uso do solo (fator CP da EUPS).

Modelagem dos Dados Geoquímicos de $\mathrm{As}$ e $\mathrm{Pb}$ Os teores de $\mathrm{As}$ e $\mathrm{Pb}$ extraídos de amostras presentes nos dois bancos de dados geoquímicos aqui utilizados (CPRM e IPT) foram interpolados pelo método Inverso do Quadrado da Distância (IQD). O método IQD baseiase na linearidade ponderada da combinação do conjunto de dados, no qual o fator de ponderação é o inverso da distância. Ou seja, esse operador pondera mais os pontos próximos das células em processamento do que aquelas mais afastadas (Voltz \& Webster 1990). Uma maior proximidade dos dados define uma superfície interpolada que possui maiores detalhes (Tsanis \& Gad 2001).

RESULTADOS Para a identificação das áreas críticas (Tab. 4) quanto à perda de solos, foram construídas quatro matrizes numéricas correspondentes aos fatores R, K, LS e CP da EUPS. Estas quatro matrizes georreferenciadas foram sobrepostas espacialmente e multiplicadas entre si através de operações de análise espacial. O resultado dessa combinação foi classificado em intervalos de interesse (Tab. 5), gerando mapas de potencial natural de erosão (Fig. 2), que representam a

Tabela 4 - Recomendações da FAO, PNUMA e UNESCO (Almorox 1994), referentes à classificação do grau de erosão hídrica.

\begin{tabular}{l|l}
\hline Perda de Solo (t/ha.ano) & Grau de Erosão \\
\hline$<10$ & Nenhuma ou Baixa \\
\hline $10-50$ & Moderada \\
\hline $50-200$ & Alta \\
\hline$>200$ & Muito Alta \\
\hline
\end{tabular}


integração dos principais fatores naturais do meio físico intervenientes no processo de erosão laminar, para os períodos de 1990 e 1999.

Os mapas da figura 2 e a tabela 5 indicam, de um modo geral, que a erosão aumentou significativamente em nove anos. $\mathrm{O}$ desmatamento parece ter sido a principal causa. A classe muito alta teve um aumento de aproximadamente $45 \%$ para um período de nove anos. As outras classes apresentaram redução nas suas
Tabela 5 - Quantificação da área das classes de erosão para os anos de 1990 e 1999.

\begin{tabular}{l|l|l}
\hline Quantificação das classes de erosão \\
\hline Ano & 1990 & 1999 \\
\hline Classe Baixa & $769,04 \mathrm{~km}^{2}$ & $733,11 \mathrm{~km}^{2}$ \\
\hline Classe Moderada & $727,55 \mathrm{~km}^{2}$ & $686,93 \mathrm{~km}^{2}$ \\
\hline Classe Alta & $321,50 \mathrm{~km}^{2}$ & $318,51 \mathrm{~km}^{2}$ \\
\hline Classe Muito Alta & $174,01 \mathrm{~km}^{2}$ & $253,56 \mathrm{~km}^{2}$ \\
\hline
\end{tabular}
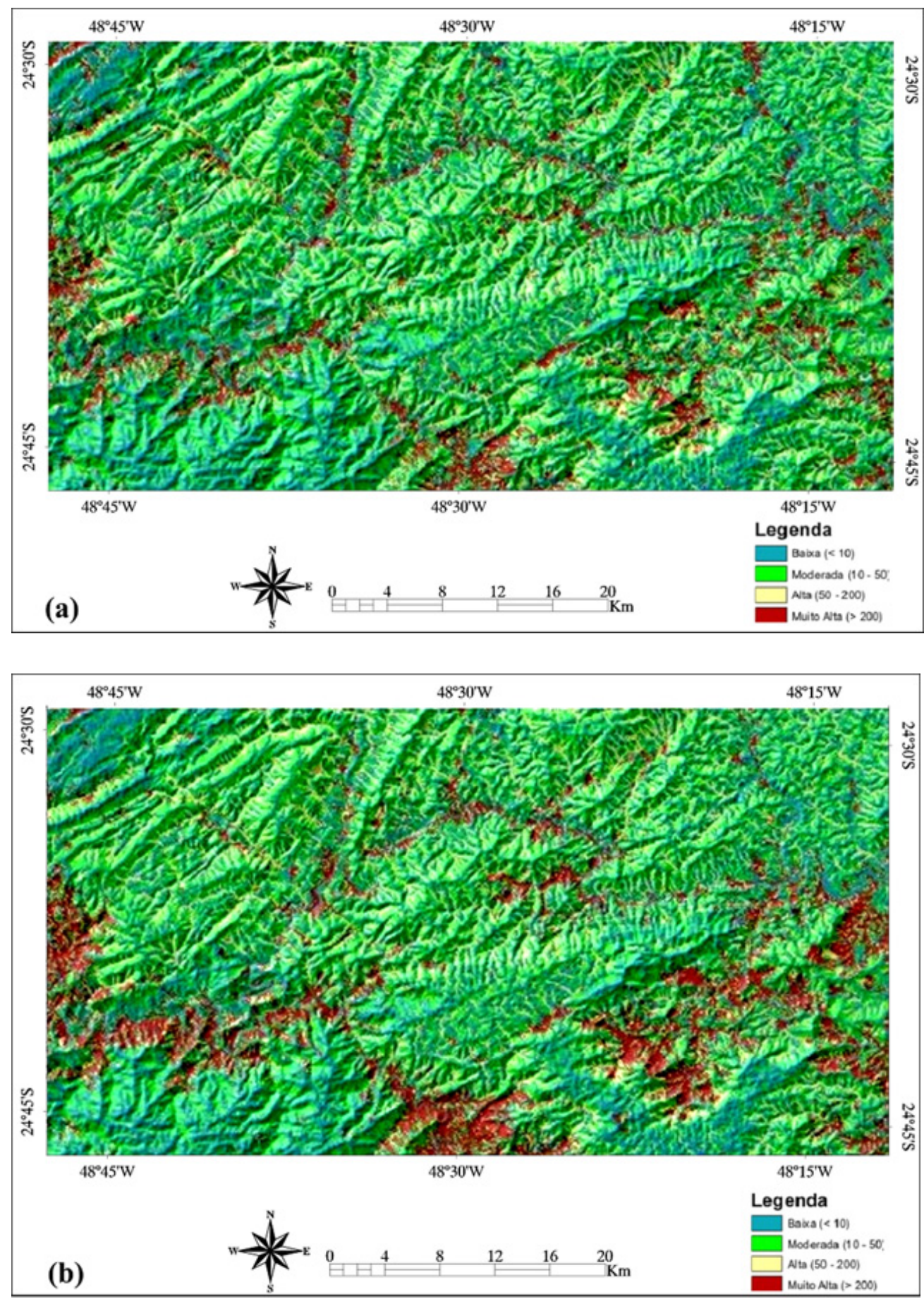

Figura 2 - Mapas de perdas de solo (t/ha.ano) por erosão hídrica para (a) 1990 e (b) 1999. Os mapas foram derivados da espacialização das variáveis do modelo $\operatorname{EUPS}(R * K * L S * C P)$. 
áreas. A distribuição espacial da perda de solos (Fig. 2) compreende uma configuração influenciada pelo fator topográfico (LS), que é a parcela de contribuição do relevo, função da declividade e comprimento de rampa. Estes fatores são determinantes para a velocidade do escoamento e caracterizam o potencial de transporte pela erosão em relação ao tamanho e quantidade de partículas. Outra variável importante é a erosividade (R) que, quanto mais intensa, maior será sua capacidade de remoção e transporte do material superficial.

O mapeamento de áreas simultaneamente mais afetadas pela erosão (e conseqüente transporte de sedimentos) e portadoras de concentrações anômalas de As $\mathrm{e} \mathrm{Pb}$ foi realizado a partir da fusão espacial do mapa de isoteores (dados interpolados) (Figs. 3 e 4 ) com os mapas temporais de erosão potencial (Fig. 2). Os mapas

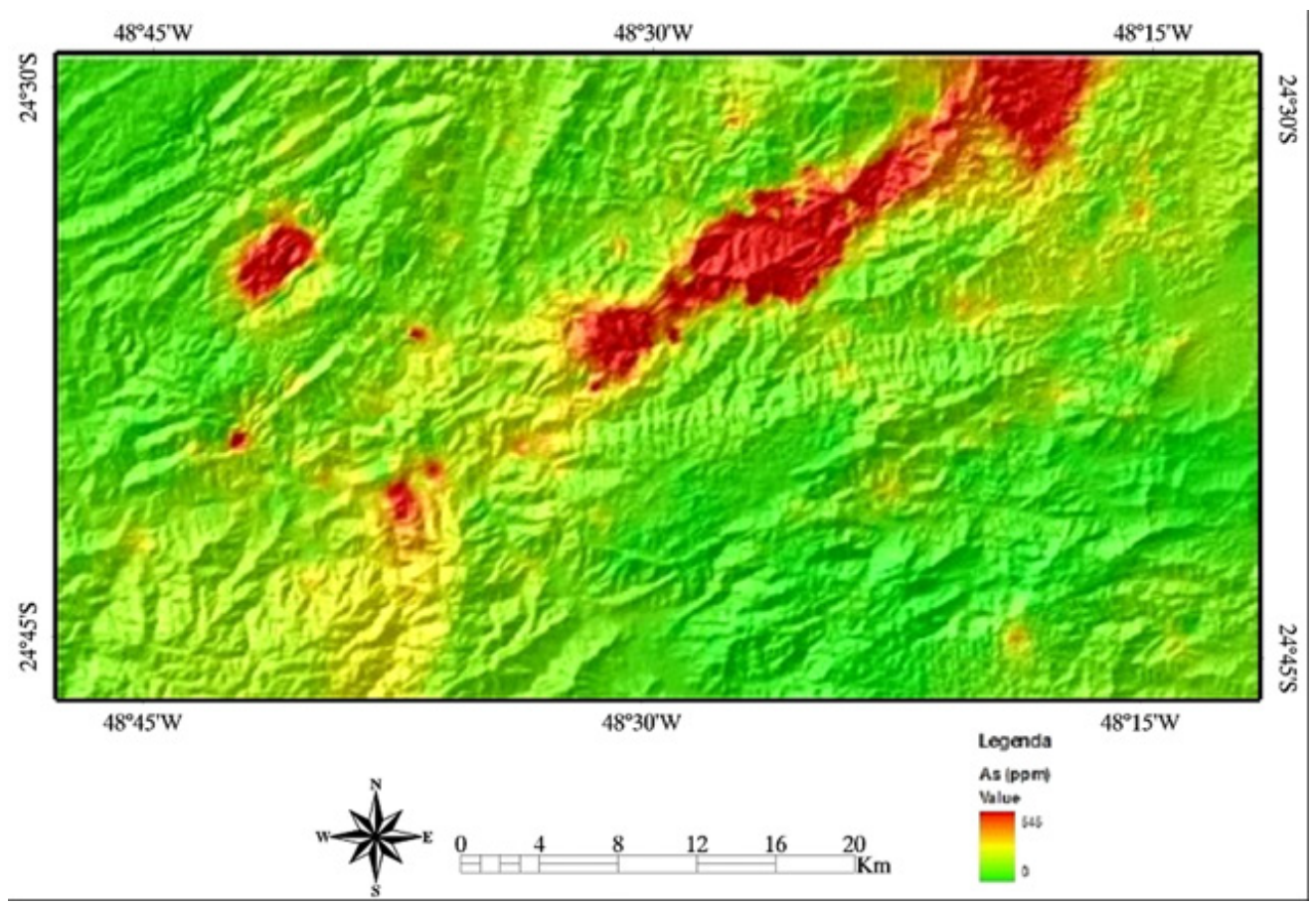

Figura 3 - Mapa de isoteores de As, interpolados pelo método IQD, a partir de dados de sedimentos de corrente.

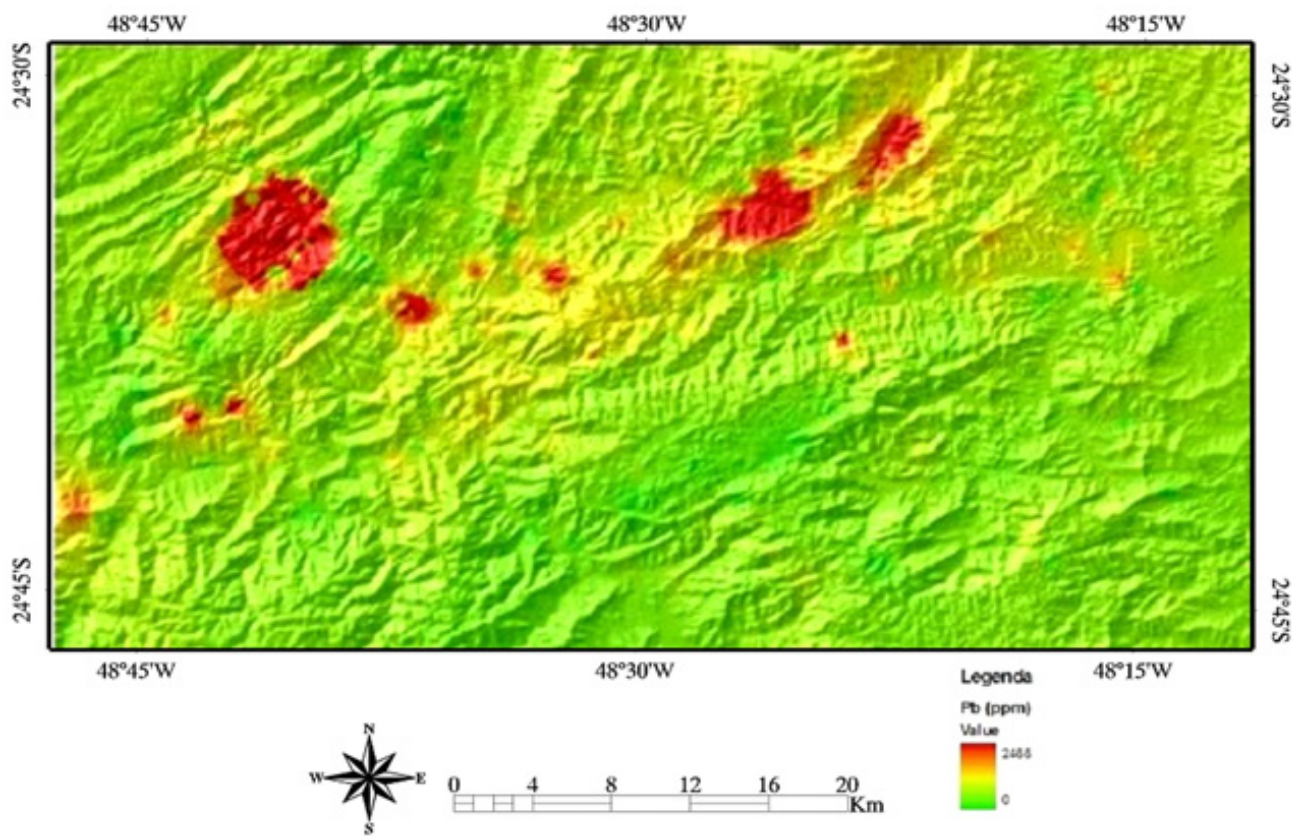

Figura 4 - Mapa de isoteores de Pb, interpolados pelo método IQD, a partir de dados de sedimentos de corrente. 
resultantes (Figs. 5 e 6 ) demonstram que na região há uma correlação entre setores onde houve um aumento significativo da erosão potencial e setores com teores elevados nesses metais. Esta relação foi também quantificada. Para os anos de 1990 e 1999, respectivamente, as áreas de maior erosão potencial e que se encontram, coincidentemente, dentro da ano- malia de As, são de aproximadamente $14 \mathrm{~km} 2$ e 16 $\mathrm{km} 2$. A mesma análise para o $\mathrm{Pb}$, revelou valores de cerca de $6 \mathrm{~km} 2$ e $8 \mathrm{~km} 2$ para o anos de 1990 e 1999 , respectivamente. Há também regiões com altos teores de $\mathrm{As}$ e $\mathrm{Pb}$ sem incremento de erosão potencial e vice-versa.
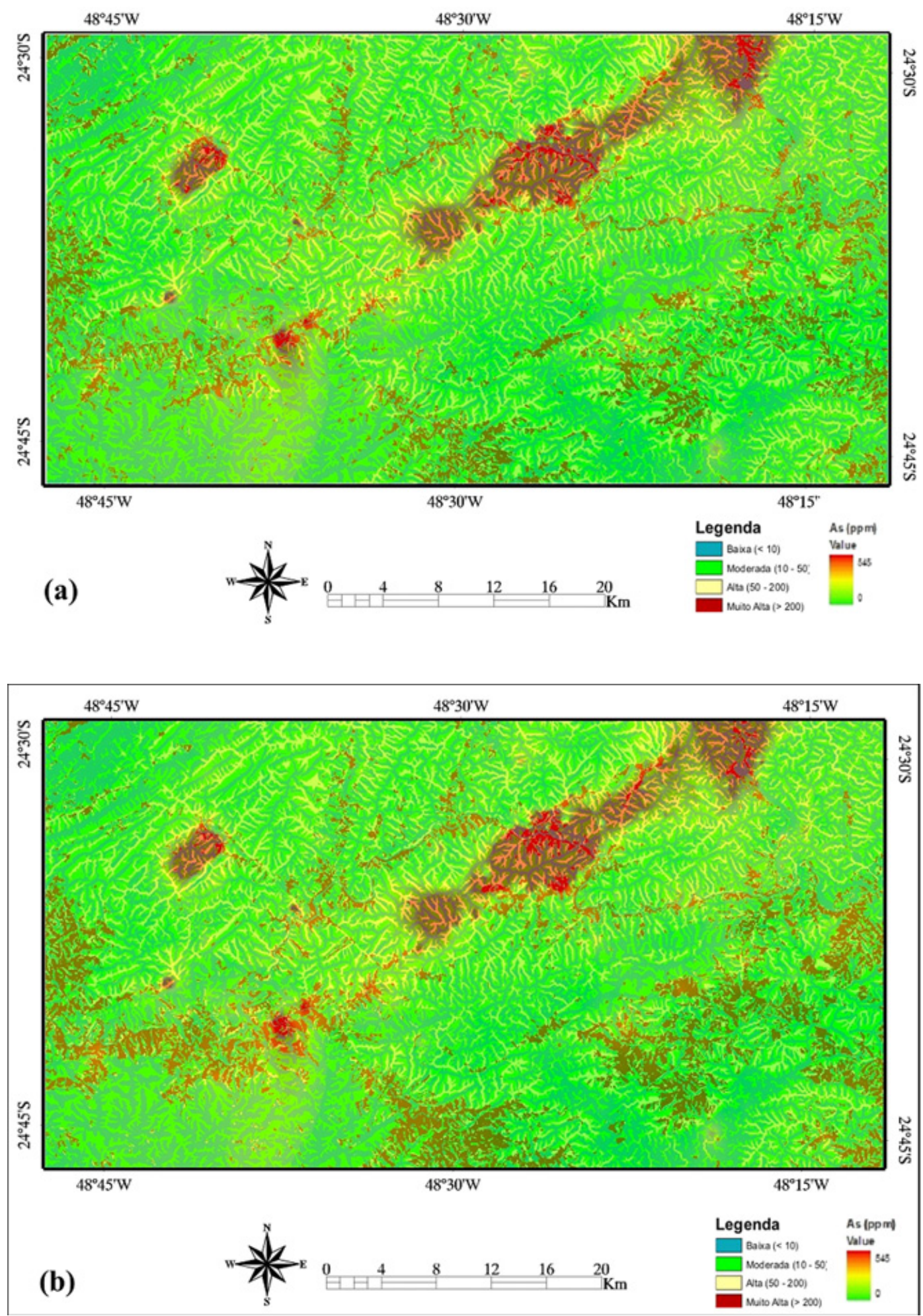

Figura 5 - Fusão espacial dos mapas de erosão potencial e isoteores de As para os anos de 1990 (a) e 1999 (b). 

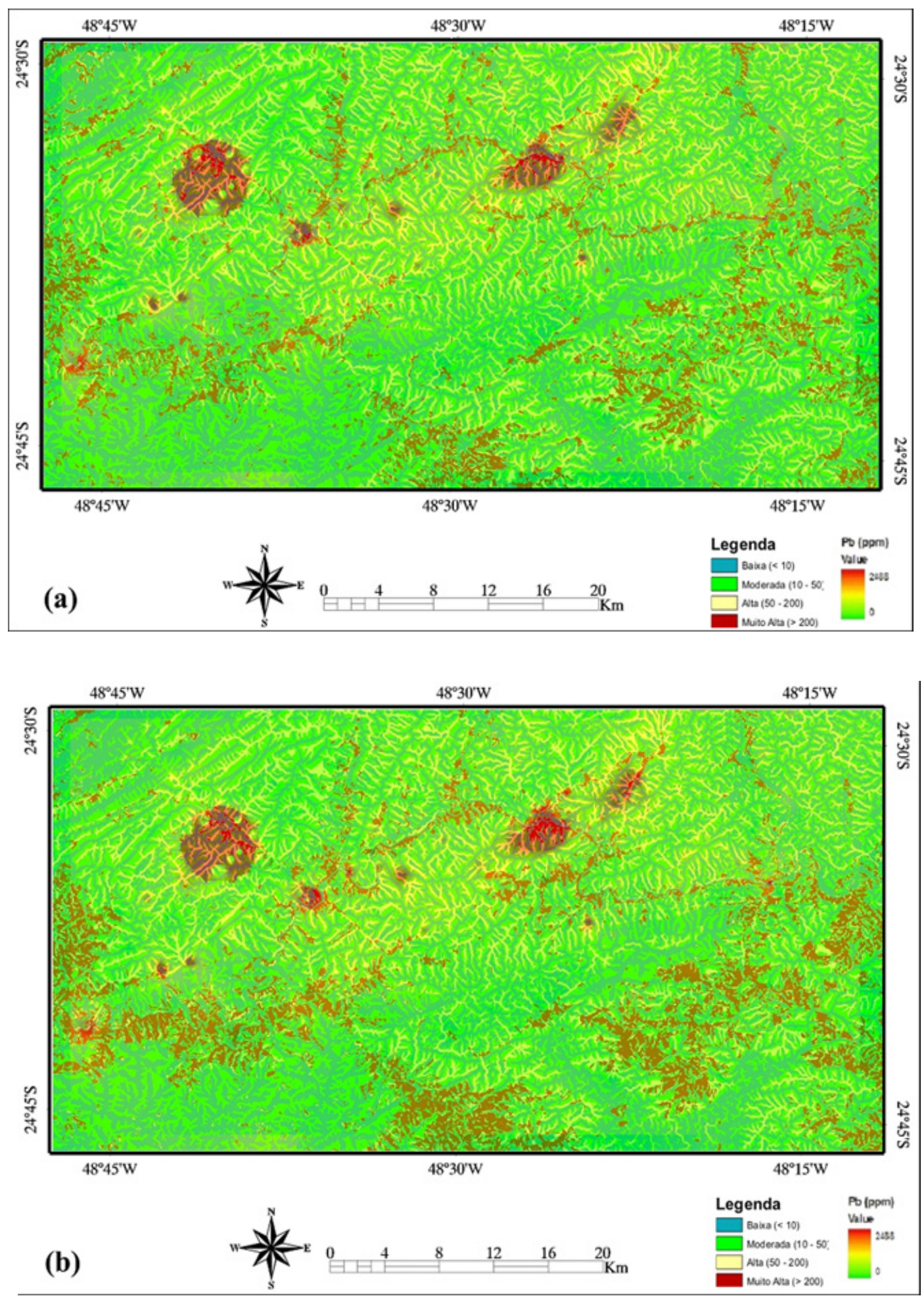

Figura 6 - Fusão espacial dos mapas de erosão potencial e isoteores de Pb para os anos de 1990 (a) e 1999 (b).

DISCUSSÕES O potencial natural de erosão foi avaliado a partir dos fatores naturais, ou seja, dos solos, por erodibilidade; do clima, por erosividade; e do relevo, por declividade e comprimento de vertentes. O efeito da falta de cobertura do solo pode ser um dos fatores mais graves no tocante ao impacto ambiental. A análise foi desenvolvida considerando-se a interação existente entre o solo e o relevo no condicionamento do potencial natural de erosão, refletindo o estreito controle exercido pela erodibilidade (K) e pelo fator topográfico (LS), este mais efetivo por parte da declividade.

Pode-se observar na figura 2 que houve um aumento de áreas degradadas pela erosão (classe muito alta), considerada de alto potencial erosivo natural. 
Como se trata de uma região escarpada, o conjunto declividade e precipitação fazem com que haja um maior escoamento e, conseqüentemente, uma predisposição à ocorrência de processos erosivos.

As figuras 5 e 6 foram geradas visando a identificação de áreas de ocorrência das anomalias de As e $\mathrm{Pb}$ e sua comparação com as áreas erodidas, buscando determinar o grau de correlação espacial entre estas variáveis (erosão e anomalias). Esta comparação auxilia na aplicação de medidas mitigadoras para controle de erosão, pois quanto maior a erosão, maior será a disponibilidade para o meio de sedimentos enriquecidos naturalmente nestes elementos tóxicos.

CONCLUSÕES Este trabalho buscou avaliar as perdas de solo por erosão laminar em uma área de estudo na Bacia do Rio Ribeira do Iguape, por meio da Equação Universal de Perda de Solos, desenvolvida por Wischmeier (1959).

Em função das limitações metodológicas originadas pela aplicação da EUPS em grandes áreas, utilizando parâmetros obtidos em pequenas parcelas experimentais, os resultados devem ser tomados somente como indicativos das perdas de solo.

O modelo utilizado neste estudo permite estimar somente a erosão laminar, sem caracterizar outros processos de erosão hídrica, assim como não permite caracterizar diretamente os processos de assoreamento. O processo de produção de sedimentos (ou seja, "o quanto sai de material sólido") da área de estudo e das suas unidades hidrográficas, poderá ser estimado a partir do balanço entre os valores obtidos para perda de solos (valor estimado) e dados obtidos em levantamentos sedimentométricos nos rios (valor medido).

$\mathrm{O}$ valor médio da erosividade (R) calculado foi de 7.294 MJ.mm/ha.h.ano. Este resultado, se comparado com as médias do Estado de São Paulo, é um índice alto. Como conseqüência, o potencial erosivo de áreas desprovidas de cobertura vegetal é maior. Outro fator importante é a erodibilidade (K). Como há diversidade de solos, algumas classes são poucas profundas e mal drenadas, tendo uma erodibilidade média a alta. Estas propriedades afetam a velocidade de infiltração, permeabilidade e capacidade de armazenamento de água, fazendo com que a presença de solos frágeis colabore com o aumento de processos erosivos.

As áreas aqui compreendidas na classe muito alta possuem uma perda de sedimentos acima de $200 \mathrm{t} /$ ha.ano e algumas regiões são coincidentes com as áreas anômalas de $\mathrm{As}$ e $\mathrm{Pb}$. Pode-se observar, na análise temporal realizada, que houve um aumento de aproximadamente $80 \mathrm{~km}^{2}(45 \%)$ desta classe entre 1990 e 1999.

A análise espacial possibilitou a quantificação da relação entre áreas mais afetadas pela erosão versus áreas portadoras de anomalias de $\mathrm{As} \mathrm{e} \mathrm{Pb}$. O resultado obtido desta análise demonstrou que para o elemento As detectou-se uma área de aproximadamente $14 \mathrm{~km} 2$ (1990) e $16 \mathrm{~km} 2$ (1999), e para o elemento chumbo uma área de 6 km2 (1990) e 8 km2 (1999). Dessa forma, estima-se que nesse período houve um aumento de aproximadamente de $14,3 \%$ para o As e $33,3 \%$ para o $\mathrm{Pb}$ nas áreas de maior erosão potencial e que se encontram relacionadas com maiores concentrações nesses metais.

Os resultados aqui apresentados demonstram que para o controle dos processos erosivos é importante uma readequação nas formas de uso, pois o solo, quando desprotegido, facilita a erosão e a disponibilidade de sedimentos enriquecidos naturalmente em $\mathrm{As}$ e $\mathrm{Pb}$. Para uma possível adequação dessa situação, duas formas básicas podem ser consideradas para controle. A primeira é uma reavaliação do uso da terra, buscando coberturas capazes de proteger o solo, já que o mesmo passou por processos de desmatamento. A segunda é a adoção de práticas conservacionistas, como por exemplo, a fragmentação do comprimento de rampa, diminuindo assim o espaço para o escoamento superficial da água.

Agradecimentos FHSC agradece ao CNPq pela concessão da bolsa de doutorado e também a Superintendência de Administração da Rede Hidrometeorológica - SAR e a ANA - Agência Nacional de Águas pelos dados pluviométricos, CPRM e IPT pelos dados geoquímicos. CRSF agradece ao CNPq pela bolsa de Produtividade em Pesquisa.

\section{Referências}

Addas W. \& Vinha C.A.G.,1975. Projeto da Sudelpa: relatório final reconhecimento geoquímico (parte 1 a 3 ). São Paulo: Sudelpa/CPRM, v. 15/17.

Alegri V., Pizzato L.G., Ferrari C.P., Addas W., Morgental L.A. 1980. Projeto Serra do Jabaquara: relatório de prospecção preliminar. São Paulo: CPRM, v. 2.

Almorox A.J. 1994. Métodos de estimación de la erosión hídrica. España, Ed. Agrícola, 152 p.

Bertoni J. \& Lombardi Neto F. 1993. Conservação do Solo. 3a ed., São Paulo, Ed. Icone, 355p.

CANADIAN COUNCIL OF MINISTERS OF THE ENVIRONMENT (CCME). 1999. Canadian water quality guidelines for the protection of agricultural water uses: Carbofuran. In: Canadian environmental quality guidelines, Canadian Council of Ministers of the Environment, Winnipeg, $3 \mathrm{p}$.

Cross A.M., Mason D.C., Dury S.J. 1988. Segmentation of remotely-sensed images by a split-and-merge process. International Journal of Remote Sensing, 9(8):13291345.

DEPARTAMENTO DE ÁGUAS E ENERGIA ELÉTRICA (DAEE). 2008. Banco de Dados Hidrometeorológicos. Disponível em http://www.daee.sp.gov.br. Acessado em Julho de 2008.

Ferreira M.E., Cruz M.C.P., Abreu C.A., Raij B.V. (eds) 2001. Micronutrientes e elementos tóxicos na agricultura. Jaboticabal-SP, Ed. Funepe, 600p.

Fonseca L.M.G. 2001. Processamento Digital de Imagens. 
São José dos Campos, INPE, 111p.

Fujihara A.K. 2002. Predição de erosão e capacidade de uso do solo numa microbacia do oeste paulista com suporte de geoprocessamento. Dissertação de Mestrado, IGUSP, $136 \mathrm{p}$.

INSTITUTO SOCIOAMBIENTAL (ISA) 1998. Diagnóstico Socioambiental do Vale do Ribeira: Documento Síntese, São Paulo, 32p.

Lin N.F. 1991. Medical Environmental Geochemistry. Changchun City of China, Jilin, Science and Technology Publishing House, p. 125-256.

Lombardi Neto F. \& Moldenhauer W.C. 1980. Erosividade da chuva: sua distribuição e relação com perdas de solo em Campinas, SP. In: Encontro Nacional de Pesquisa sobre Conservação do Solo, Recife, atas?, p. 13.

Lopes V.L. 1980. Um Estudo da Erosão e Produção de Sedimentos Pelas Chuvas. Mossoró, Escola Superior de Agricultura de Mossoró, $71 \mathrm{p}$.

Lopez M.T. 1993. WEPP (Water erosion Prediction Project): un modelo basado en procesos fisicos para simular erosion hidrica. In: Intl. Seminar of Watershed Management, 1, Hermo Sillo, Sonora, México, Proceedings, p. 119.

Morgental A., Batolla Jr. F., Pinto G.G., Paiva I.P., Drumond J.B.V. 1975. Projeto Sudelpa: relatório final. São Paulo, SUDELPA/CPRM, v. 18.

Morgental A., Silva A.A.G.P., Borin Jr. T., Alegri V., Oliveira P.E.P. 1978. Projeto geoquímica no Vale do Ribeira: relatório final. São Paulo, DNPM/CPRM, v. 8.

Nimer E. 1977. Clima. In: IBGE (ed.) Geografia do Brasil, Região Sudeste. Rio de Janeiro, SERGRAF/IBGE, v.3, p. 51-89.

Perrotta M.M., 1996. Potencial aurífero de uma região no Vale do Ribeira, São Paulo, estimado por modelagem de dados geológicos, geofísicos, geoquímicos e de sensores remotos num sistema de informações geográficas. São Paulo, Tese de Doutoramento, IG/USP, 149 p.

Ranieri S.B.L., Sparovek G., Souza M.P., Dourado Neto D. 1998. Aplicação de índice comparativo na avaliação do risco de degradação das terras. Revista Brasileira de Ciência do Solo, 22(4):751-760.

Resende M. \& Almeida J.R. 1985. Modelos de Predição de Perdas de Solo: Uma ferramenta para Manejo e Conservação do Solo. Inf. Agropecuário, 11(128):3853.

Risso A., Reis L.G. de M., Paz A., Lima H.V.C. 2005. Estimativa da produção de sedimentos de forma distribuída usando a equação universal de perdas de solo (EUPS) e geoprocessamento: aplicação na bacia do Lago Guaíba (RS). In: Simpósio Brasileiro de Recursos Hídricos, 16, João Pessoa (PB), Anais, p. 21-29.

Silva M.R.C. 2002. Estudos de sedimentos da bacia hidrográfica do Mogi-Guaçu, com ênfase na determinação de metais. Dissertação de Mestrado, IQUSP, São Carlos, 113p.

Silva A.A.G.P. 1982. Projeto Serra do Jabaquara: relatório preliminar de pesquisa de ouro, cobre, chumbo, e zinco do município de Capão Bonito (SP). São Paulo, CPRM, v. 2.

Tsanis I.K. \& Gad M.A. 2001. A GIS Precipitation Method for Analysis of Storm Kinematic. Environmental Modelling \& Software, 16:273-281.

Valeriano M.M. 2005. Modelo digital de variáveis morfométricas com dados SRTM para o território nacional: o projeto TOPODATA. In: Simpósio Brasileiro de Sensoriamento Remoto, 12, Goiânia, Brasil, Anais, p. 3595-3602.

Valeriano M.M. 2002. Modelos digitais de elevação de microbacias elaborados com krigagem. Relatório Técnico, INPE-9364-RPQ/736.

Voltz M. \& Webster R. 1990. A comparison of kriging, cubic splines and classification for predicting soil properties from sample information. J. Soil Sci., 41:473-490.

Van Oost K. \& Govers G. 2000. Usle2D - LS-factor in the Universal Soil Loss equation from a grid-based Digital elevation model. Disponível em http://www.kuleuven. be/geography/frg/modelling/erosion/usle2dhome/. Acessado em Julho de 2008.

Wang M-Y. \& Zhang S. 1985. The discussion on biogeochemical area and endemic disease. Sci Sinica, B28 (9):932-936.

Wischmeier W.H. 1959. A rainfall erosion index for a uiversal soil loss equation. Soil Sci. Soc. Amer. Proc., 23:246249.

White I.D., Matershead D.N., Harrison S.J. 1992. Environmental Systems. 2 ed., Londres, Chapman \& Hall, 632p.

Zwennis W.C.M., Franssen A.C., Wijnas M.J. 1990. Use zinc protoporphyrin in screening individuals for exposure for lead. Clin. Chem., 26(8):1456-1459.

Manuscrito ID 12287

Submetido em 18 de setembro de 2008 Aceito em 24 de junho de 2009 